\title{
Scientific Research Papers of Lecturers from the Faculty of Sport and Physical Education in Niksic Published in Sport Mont Journal in Last Three Years
}

\author{
Pavle Malovic ${ }^{1}$ \\ 'University of Montenegro, Faculty for Sport and Physical Education, Niksic, Montenegro
}

\begin{abstract}
Sport Mont is electronic and printed scientific journal and also official journal of Montenegrin Sports academy which was established 2003. SMJ is published three times a year by the Montenegrin sport academy (MSA) and in it is possible to find more than 1400 papers from various fields of sport science from word wide known scientists. In last three years more than 100 papers are published in this journal. Lecturers from Faculty for sport and physical education published 28 papers in mentioned period and in this research were analysed and classified papers of following fields of sport science: anthropology, sport training, management and marketing in sport, sports physiology, theory of sport and physical culture, history of sport, nutrition and other areas of sport. Papers have been classified according to the scientific fields they belong to and the most published papers are from anthropology field of science (15). Interesting to mention is that lecturers with the most and the same number of published articles are Jovan Gardasevic and Bojan Masanovic who have 12 each (22,67\%) published articles. This research can be useful for further theoretical research, as well as for theoreticians.
\end{abstract}

Key words: Sport Mont Journal, Sport Science, Analysis, Montenegrin Sports Academy

\section{Uvod}

Sport Mont je zvanični časopis Crnogorske sportske akademije (CSA) koji je pokrenut 2003. godine, a za čije su osnivanje zaslužni CSA i njen predsjednik Duško Bjelica. U ovom časopisu, koji izlazi tri puta godišnje, može se naći preko 1400 radova koji pokrivaju mnoge aspekte sportske nauke. Naučni časopis "Sport Mont" predstavlja objedinjavanje saznanja prakse i teorije, a samim tim i šire sagledavanje mnogih drugih, bitnih pitanja vezanih za sport. U ovom časopisu je moguće naći originalne naučne radove, pregledne radove, uvodnike, kratke izvještaje, kao i poziv i nagrade radova u oblasti sportskih nauka i medicine. Takođe funkcioniše i kao otvoreni forum za diskusiju o značajnim aktuelnim pitanjima, a autori koji objavljuju u njemu su naučnici kako iz naše zemlje, zemalja iz regiona, tako i iz cijelog svijeta. Kao i svaki početak, i onaj koji se veže za razvoj i afirmaciju časopisa "Sport Mont" bio je težak. Ali mukotrpnim radom uredništva situacija se mijenjala, radovi koji su objavljivani postajali su kvalitetniji i "Sport Mont" je postao renomiran časpis u svijetu nauke. U prilog tome govori činjenica da je februarsko izdanje 2019. godine pomenutog časopisa indeksirano u 44 međunarodne baze, od kojih je najznačajnija Scopus. Svrha časopisa je promocija sportske nauke kako u Crnoj Gori, tako i van nje.

\section{Metod}

Za ovo istraživanje korišćena je metoda analize sadržaja. Metoda analize sadržaja se koristi za objektivnu sistemsku i kvantitativnu analizu očiglednog sadržaja saopštenja (filmova, knjiga, štampe, kao i elektronskih sadržaja). Jedinica koja je analizirana u ovom radu su naslovi radova objavljenih od strane predavača sa Fakulteta za sport i fizičko u Nikšiću u poslednje tri godine u časopisu „Sport Mont“.

\section{Montenegro}

Gport

\section{Correspondence:}

P. Malovic

University of Montenegro, Faculty for Sport and Physical Education, Narodne omladine bb, 81400 Niksic, Montenegro

E-mail: pavle.m@ucg.ac.me 


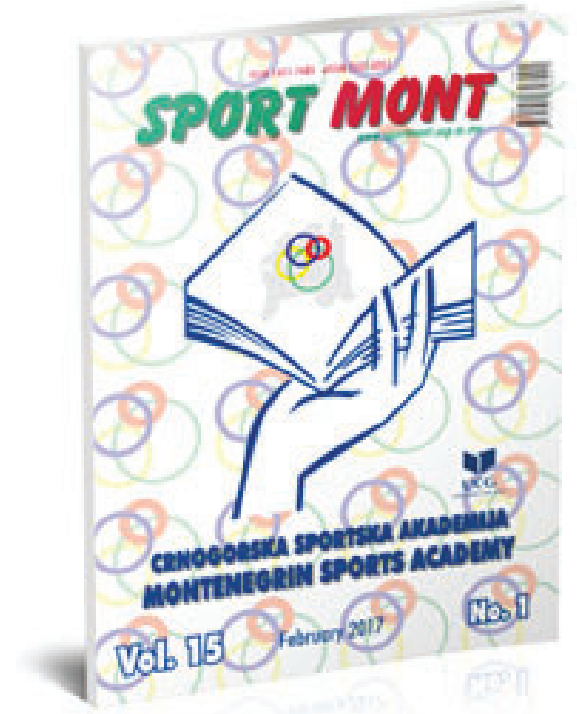

Slika 1. Časopis Sport Mont Vol. 15 No. 1 (2017)

U tom periodu objavljeno je 28 radova predavača sa pomenute univerzitetske jedinice. Dakle, istraživački radovi u ovoj analizi sadržaja su klasifikovani po oblastima kojima pripadaju, a izdvo- jene su sljedeće oblasti: antropologija, sportski trening, fiziologija sporta, Sportski menadžment i marketing u sportu, nutricionizam, teorija sporta i fizičke kulture, istorija sporta i ostali radovi.

Tabela 1. Klasifikacija objavljenih radova prema naučnim oblastima

\begin{tabular}{cc}
\hline Naučne discipline & Broj objavljenih radova \\
\hline Antropologija & 15 \\
Sportski trening & 3 \\
Fiziologija sporta & 1 \\
Sportski menadžment i marketing u sportu & 3 \\
Nutricionizam & 1 \\
Teorija sporta i fizičke kulture & 1 \\
Istorija sporta & 1 \\
Ostali radovi & 3 \\
Total & 28 \\
\hline
\end{tabular}

\section{Rezultati}

Nakon detaljne analize i pregleda časopisa "Sport Mont" u poslednje tri godine izdvojeni su radovi 12 predavača sa $\mathrm{Fa}$ kulteta za sport i fizičko vaspitanje, a ukupan broj radova je iznosio 28. Najbrojniji radovi su bili iz oblasti antropologije koja predstavlja nauku o čovjeku, odnosno o njegovim sposobnostima i karakteristikama. Radovi iz pomenute oblasti su sljedeći: „Sport-specific morphology profile: Differences in anthropometric characteristics among elite soccer and handball players" (Gusic, Popovic, Molnar, Masanovic, \& Radakovic, 2017), Waist circumference as an indicator abdominal obesity in middle age" (Vasiljevic, Gardasevic, Kezunovic, \& Bojanic, 2017), „Standing height and its estimation utilizing foot length measurements in adolescents from western region in Kosovo" (Popovic, Gardasevic, Masanovic, Arifi, \& Bjelica, 2017), „Relationship between foot length measurements and body height: A prospective regional study among adolescents in eastern region of Kosovo“ (Masanovic, Gardasevic, \& Arifi, 2018), „Relationship between sitting height measurements and standing height: a prospective regional study among adolescents in eastern region of Kosovo“ (Gardasevic, 2018), „Relationship between foot length measurements and standing height: a prospective regional study among adolescents in southern region of Kosovo“ (Masanovic, Gardasevic, \& Arifi, 2018), „Stature and its estimation utilizing arm span measurements of both gender adolescents from southern region in Kosovo" (Arifi, Sermaxhaj, Gardasevic, Alaj, \& Metaj, 2018), „Differences in the morphological characteristics and body composition of football players of hsc Zrinjski Mostar and fc Siroki Brijeg in Bosnia and Herzegovina" (Corluka, Bjelica, Vasiljevic, Bubanja, Georgiev, \& Zeljko, 2018), „Standing height and its estimation utilizing arm spam and foot length measurements in dinaric alps population: a systematic review“ (Masanovic, 2018), „Comparative study of anthropometric measurement and body composition between junior basketball and volleyball players from Serbian national league“ (Masanovic, 2018), „Relationship between tibia length measurements and standing height: A prospective regional study among adolescents in southern region of Kosovo" (Gardasevic, Masanovic, \& Arifi, 2018), „Relationship between foot length measurements and body height: A prospective regional study among adolescents in central region of Kosovo" (Arifi, Gardasevic, \& Masanovic, 2018),. „Comparative study of anthropometric measurement and body composition between junior soccer and volleyball players from the Serbian national league“ (Masanovic, Bavcevic, \& Bavcevic, 2019), „Differences in anthropometric characteristics among junior soccer and handball players“ (Arifi, Bjelica, \& Masanovic, 2019) i „Elite Football Players from Bosnia and Herzegovina and Kosovo and their Body Composition" (Gardesevic, Bjelica, Corluka, \& Vasiljevic, 2019). 
Iz oblasti sportskog treninga, koji predstavlja specifičan proces adaptacije organizma na određene stimuluse, koji se planski sprovode kako bi se ostvario maksimalan učinak u planiranoj aktivnosti objavljeni su sljedeći radovi: „The strength of kicking the ball after preparation period with U15 football players“ (Gardasevic, Bjelica, \& Vasiljevic, 2017), „The impact of the preparation period on endurance at football players U16“ (Gardasevic, Bjelica, \& Corluka, 2018), „Shooting ball accuracy with U16 soccer players after preparation period“ (Gardasevic, \& Bjelica, 2019).

U protekle tri godine takođe je objavljen rad iz oblasti fiziologije sporta, koja proučava funkcije organizma sportiste tokom fizičke aktivnosti, a to je „Structure of cognitive abilities and skills of lifeguards" (Ljubojevic, Muratovic, \& Bubanja, 2017).

Iz oblasti sportskog menadžmenta i marketinga u sportu su objavljeni sljedeći radovi: „Attitudes of consumers from Autonomous Province of Vojvodina toward advertising through sport in relation with the frequency of watching sports events" (Masanovic, 2018), Attitudes of consumers from autonomous Province of Vojvodina toward advertising through sport for the question: how often do consumers purchase sporting goods" (Milosevic, Bjelica, \& Masanovic, 2019) i „Beliefs about the Influence on Attitudes of Turkish University Students toward Advertising through Sport" (Popovic, 2019).

Iz oblasti nutricionizma je objavljen rad pod nazivom "Age and gender differences in nutritional status of school children according to WHO, CDC and IOTF references: a statewide study from Montenegro" (Milasinovic, Bojanic, Cvorovic, \& Kukic, 2019).
Jedan rad je objavljen iz oblasti teorije sporta i fizičke kulture, a to je „Theories of tiredness in sport" (Krivokapic, 2017).

Jedan rad objavljen iz oblasti istorije sporta, a to je „Historical development of skiing: Case study in Durmitor area" (Milasinovic, \& Bjelica, 2017).

Takođe, u protekle tri godine objavljeni su i radovi koje smo nazvali ostali radovi, a to su sljedeći radovi: „Repulsion of the futsal ball depending on the pressure in it" (Bjelica, Milosevic, Talovic, \& Bajramovic, 2018), „Research and writing development in the area of sport science publishing in Montenegro" (Popovic, 2018) i "Who play for the national football team of Montenegro, Montenegrins or "Montenegrins"?" (Popovic, 2019).

Nakon što se napravila klasifikacija radova prema oblastima bilo bi interesantno navesti i autore koji su se posvetili naučno istraživačkom radu u pomenutom periodu. Kao što je već navedeno aktivnost je zabilježena čak od strane 12 predavača sa Fakulteta za sport i fizičko vaspitanje. U ovom dijelu će biti prikazana ukupna aktivnost predavača, odnosno rad će biti prikazan bilo da je na njemu istraživač bio samostalni, vodeći ili koautor. Ovo nam govori da će broj radova biti mnogo veći od onoga koji je obuhvaćen u Tabeli 1. jer se jedan rad može pronaći kod više autora u zavisnosti upravo od ove tri već pomenute kategorije. Dakle, Jovan Gardašević je objavio ukupno 12 radova od čega je na jednom bio samostalni, na pet kao vodeći autor i na šest kao koautor. Bojan Mašanović je objavio 12 radova od kojih je na tri bio samostalni autor, na tri vodeći autor i na preostalih šest koautor.

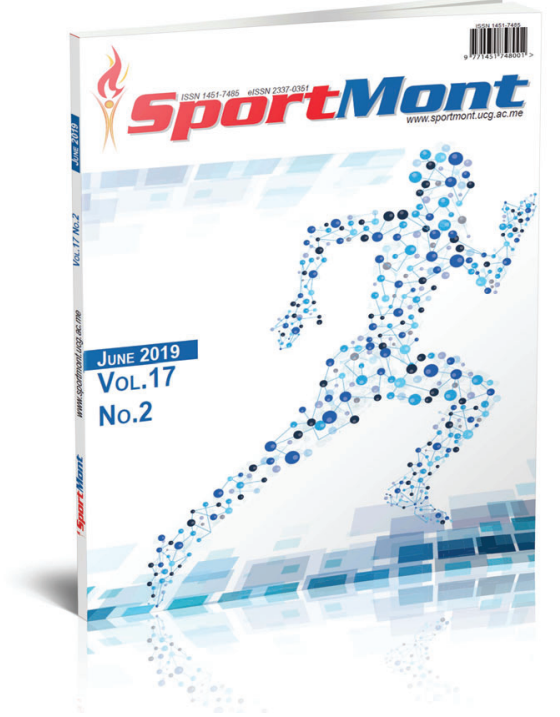

Slika 2. Časopis Sport Mont Vol. 17 No. 2 (2019)

Duško Bjelica, koji je najviše izdatih radova imao iz oblasti sportskog treninga i antropologije, u periodu od posljednje tri godine u Sport Mont časopisu objavio je deset radova, od kojih je na jednom bio vodeći autor, a na ostalih devet koautor. Stevo Popović je imao ukupno objavljenih pet radova od kojih je samostalni autor bio na tri rada, vodeći autor na jednom radu i koautor takođe na jednom radu. Ivan Vasiljević je objavio četiri rada od kojih je na jednom bio vodeći autor, a na preostala tri koautor. Rajko Milašinović je objavio dva rada, od kojih je na oba bio vodeći autor. Danilo Bojanić i Marija Bubanja je objavili su po dva rada, i na oba rada su bili koautori. Milovan Ljubojević, Aldijana Muratović, Miroslav Kezunović i Dragan Krivokapić su objavili po jedan rad, Milovan Ljubojević je na svom bio vodeći autor, Aldijana Muratović i Miroslav Kezunović koautori, dok je Dragan Krivokapić bio samostalni autor. 
Tabela 2.Brojčani i procentualni prikaz objavljenih radova predavača sa Fakulteta za sport i fizičko vaspitanje u Nikšiću u Sport Mont časopisu u periodu od posljednje tri godine

\begin{tabular}{|c|c|c|c|c|c|}
\hline PREDAVAČ & $\begin{array}{l}\text { SAMOSTALNI } \\
\text { AUTOR }\end{array}$ & $\begin{array}{l}\text { VODEĆI } \\
\text { AUTOR }\end{array}$ & KOAUTOR & $\begin{array}{l}\text { UKUPAN } \\
\text { BROJ } \\
\text { RADOVA }\end{array}$ & $\%$ \\
\hline Jovan Gardašević & 1 & 5 & 6 & 12 & 22,67 \\
\hline Bojan Mašanović & 3 & 3 & 6 & 12 & 22,67 \\
\hline Duško Bjelica & 0 & 1 & 9 & 10 & 18,86 \\
\hline Stevo Popović & 3 & 1 & 1 & 5 & 9,43 \\
\hline Ivan Vasiljević & 0 & 1 & 3 & 4 & 7,54 \\
\hline Rajko Milašinović & 0 & 2 & 0 & 2 & 3,77 \\
\hline Danilo Bojanić & 0 & 0 & 2 & 2 & 3,77 \\
\hline Marija Bubanja & 0 & 0 & 2 & 2 & 3,77 \\
\hline Milovan Ljubojević & 0 & 1 & 0 & 1 & 1,88 \\
\hline Aldijana Muratović & 0 & 0 & 1 & 1 & 1,88 \\
\hline Dragan Krivokapić & 1 & 0 & 0 & 1 & 1,88 \\
\hline Miroslav Kezunović & 0 & 0 & 1 & 1 & 1,88 \\
\hline TOTAL & 8 & 14 & 31 & 53 & 100 \\
\hline
\end{tabular}

\section{Diskusija}

U ovom radu su klasifikovani naslovi koji su objavljeni u periodu u protekle tri godine u „Sport Mont“ časopisu, a na kojima su radili isključivo predavači sa Fakulteta za sport i fizičko vaspitanje. Naime, iz priloženog se može viđeti da je najviše objavljenih radova iz oblasti antropologije, odnosno više od pola ukupnog broja objavljenih radova. Nakon ove oblasti, za istraživače pomenute univerzitetske jedinice, najinteresantnija je bila oblast sportskog treninga i menadžmenta i marketinga u sportu sa po tri objavljena rada iz pomenutih naučnih oblasti. Nakon toga slijede i ostale, u radu prikazane oblasti sa po jednim objavljenim radom. Takođe, u okviru ove studije, pored klasifikacije radova prema oblastima analizirana je naučno-istraživačka aktivnost predavača sa Fakuteta za sport i fizičko vaspitanje koji su objavili radove u posljednje tri godine u časopisu Sport Mont. Naime, prikazan je broj objavljenih radova svih autora, bilo da su na tim radovima bili samostalni autori, vodeći ili koautori, pa se upravo iz tog razloga mnogi od radova ponavljaju više od jednog puta. Razlog tome i adekvatno objašnjenje je da predavači na Fakultetu za sport i fizičko vaspitanje u Nikšiću na mnogim naučno-istraživačkim radovima sarađuju, a sve u cilju kvalitetnijeg materijala koji će dospjeti kod renomiranih recenzenata, a nakon toga i objaviti u samom časopisu koji je, kako je već navedeno, na zavidnom nivou u svijetu sportske nauke. Dakle, kao što se može viđeti u Tabeli 2. najviše objavljenih radova, odnosno po $12(22,67 \%)$, imaju Jovan Gardašević i Bojan Mašanović, dok je odmah iza njih Duško Bjelica sa deset $(18,86 \%)$ objavljenih radova. Ukoliko sagledamo broj objavljenih radova kao samostalnih autora na publikovanom radu najviše objavljenih radova imaju Bojan Mašanović i Stevo Popović (3), dok najviše objavljenih radova kao vodeći autor ima Jovan Gardašević (5). Na samom kraju, Duško Bjelica ima najviše objavljenih radova kao koautor (9). $\mathrm{Na}$ osnovu navedenog možemo zaključiti da predavači sa pomenute univerzitetske jedinice daju izuzetan doprinos nauci svojim angažovanjem i naučno-istraživačkim radom. Jasno je da dobar predavač i sportski radnik mora pratiti tokove i mora biti upoznat sa posljednim dešavanjima i inovacijama u svijetu sporta i fizičke kulture. Shodno tome, u ovom radu se jasno vidi da predavači sa Fakulteta za sport i fizičko vaspitanje u Nikšiću praktikuju da budu uključeni u svim dešavanjima, a sve kako bi omogućili kvalitetniju kako praktičnu, tako i teorijsku nastavu. Činjenica da je za postizanje kvaliteta neophodna saradnja kako između istraživača sa Fakulteta za sport i fizičko vaspitanje, tako i sa drugim istraživačima zemalja iz regiona i svijeta iz raznih oblasti, potkrijepljuje se riječima jednog od istraživača sa britanskog univerziteta u Laboru, Ines Varela-Silve koji navodi da sport ne može da se odvoji od društva i kao takav ne bi mogao da postoji, jer se upravo odnosi na sve njegove segmente i ukoliko se želi postići multidisciplinarnost ili interdisciplinarnost mora se sarađivati sa ljudima iz drugih naučnih oblasti (Maros, 2017).

\section{Acknowledgements}

There are no acknowledgements.

\section{Conflict of Interest}

The authors declare that there are no conflicts of interest.

Received: 7 May 2019| Accepted: 31 May 2019| Published: 4 July 2019

\section{References}

Arifi, F., Sermaxhaj, S., Gardasevic, J., Alaj, I., \& Metaj, Z. (2018). Stature and its estimation utilizing arm span measurements of both gender adolescents from southern region in Kosovo. Sport Mont, 16(2), 51-54. doi: $10.26773 /$ smj.180609

Arifi, F., Gardasevic, J., \& Masanovic, B. (2018). Relationship between foot length measurements and body height: A prospective regional study among adolescents in central region of Kosovo. Sport Mont, 16(3), 7579. doi: $10.26773 / \mathrm{smj}$.181013

Arifi, F., Bjelica, D., \& Masanovic, B. (2019). Differences in anthropometric characteristics among junior soccer and handball players. Sport Mont, 17(1), 45-49. doi: 10.26773/smj.190208

Bjelica, D., Milosevic, Z., Talovic, M., \& Bajramovic, I. (2018). Repulsion of the futsal ball depending on the pressure in it. Sport Mont, 16(2), 6167. doi: 10.26773/smj.180611

Corluka, M., Bjelica, D., Vasiljevic, I., Bubanja, M., Georgiev, G., \& Zeljko, I. (2018). Differences in the morphological characteristics and body composition of football players of hsc Zrinjski Mostar and fc Siroki Brijeg in Bosnia and Herzegovina. Sport Mont, 16(2), 77-81. doi: 10.26773/smj.180614

Gardasevic, J. (2018). Relationship between sitting height measurements and standing height: a prospective regional study among adolescents in eastern region of Kosovo. Sport Mont, 16(2), 15-19. doi: $10.26773 / \mathrm{smj} .180603$

Gardasevic, J., Bjelica, D., \& Vasiljevic, I. (2017). The strength of kicking the ball after preparation period with U15 football players. Sport Mont, 15(2), 39-42.

Gardasevic, J., Bjelica, D., \& Corluka, M. (2018). The impact of the preparation period on endurance at football players U16. Sport Mont, 16(1), 21-24. doi: $10.26773 /$ smj.180204 
Gardasevic, J., Masanovic, B., \& Arifi, F. (2018). Relationship between tibia length measurements and standing height: $A$ prospective regional study among adolescents in southern region of Kosovo. Sport Mont, 16(3), 51-55. doi: 10.26773/smj.181009

Gardasevic, J., \& Bjelica, D. (2019). Shooting ball accuracy with U16 soccer players after preparation period. Sport Mont, 17(1), 29-32. doi: 10.26773/smj.190205

Gusic, M., Popovic, S., Molnar, S., Masanovic, B., \& Radakovic, M. (2017) Sport-specific morphology profile: Differences in anthropometric characteristics among elite soccer and handball players. Sport Mont 15(1), 3-6.

Gardasevic, J., Bjelica, D., Corluka, M., \& Vasiljevic, I. (2019). Elite football players from bosnia and herzegovina and kosovo and their body composition. Sport Mont, 17(2), 75-79. doi: 10.26773/smj.190613

Krivokapic, D. (2017). Theories of tiredness in sport. Sport Mont, 15(1), 3537.

Ljubojevic, M., Muratovic, A., \& Bubanja, M. (2017). Structure of cognitive abilities and skills of lifeguards. Sport Mont, 15(1), 27-29.

Maros, M., (2017). A Content Analysis of Published Articles in Montenegrin Journal of Sports Science and Medicine from 2012 to 2017. Journal of Anthropology of Sport and Physical Education, 1(1), 9-15.

Masanovic, B. (2018). Standing height and its estimation utilizing arm spam and foot length measurements in dinaric alps population: a systematic review. Sport Mont, 16(2), 101-106. doi: 10.26773/smj.180619

Masanovic, B. (2018). Comparative study of anthropometric measurement and body composition between junior basketball and volleyball players from Serbian national league. Sport Mont, 16(3), 19-24. doi: $10.26773 /$ smj.181004

Masanovic, B. (2018). Attitudes of consumers from Autonomous Province of Vojvodina toward advertising through sport in relation with the frequency of watching sports events. Sport Mont, 16(3), 91-96. doi: 10.26773/smj.181016

Masanovic, B., Gardasevic, J., \& Arifi, F. (2018). Relationship between foot length measurements and body height: A prospective regional study among adolescents in eastern region of Kosovo. Sport Mont, 16(1), 9-13. doi: $10.26773 /$ smj.180202
Masanovic, B., Gardasevic, J., \& Arifi, F. (2018). Relationship between foot length measurements and standing height: a prospective regional study among adolescents in southern region of Kosovo. Sport Mont, 16(2), 27-31. doi: 10.26773/smj.180605

Masanovic, B., Bavcevic, T., \& Bavcevic, I. (2019). Comparative study of anthropometric measurement and body composition between junior soccer and volleyball players from the Serbian national league. Sport Mont, 17(1), 9-14. doi: 10.26773/smj.190202

Milasinovic, R., \& Bjelica, D. (2017). Historical development of skiing: Case study in Durmitor area. Sport Mont, 15(1), 39-41.

Milasinovic, R., Bojanic, D., Cvorovic, A., \& Kukic, F. (2019). Age and gender differences in nutritional status of school children according to who, cdc and iotf references: a statewide study from Montenegro. Sport Mont, 17(1), 15-21. doi: 10.26773/smj.190203

Milosevic, Z., Bjelica, D., \& Masanovic, B. (2019). Attitudes of consumers from autonomous province of vojvodina toward advertising through sport for the question: how often do consumers purchase sporting goods. Sport Mont, 17(1), 39-43. doi: 10.26773/smj.190207

Popovic, S., Gardasevic, J., Masanovic, B., Arifi, F., \& Bjelica, D. (2017). Standing height and its estimation utilizing foot length measurements in adolescents from western region in Kosovo. Sport Mont, 15(3), 3-7. doi: 10.26773/smj.2017.10.001

Popovic, S. (2018). Research and writing development in the area of sport science publishing in Montenegro. Sport Mont, 16(3), 31-36. doi: 10.26773/smj.181006

Popovic, S. (2019). Who play for the national football team of Montenegro, Montenegrins or "Montenegrins"?. Sport Mont, 17(1), 101-103. doi: 10.26773/smj.190220

Popovic, S. (2019). Beliefs about the influence on attitudes of turkish university students toward advertising through sport. Sport Mont, 17(2), 9-15. doi: $10.26773 / \mathrm{smj} .190602$

Vasiljevic, I., Gardasevic, J., Kezunovic, M., \& Bojanic, D. (2017). Waist circumference as an indicator abdominal obesity in middle age. Sport Mont, 15(1), 21-22. 